\title{
Prevalence of Diabetes and Associated Risk Factors in Elderly Rural Population
}

\author{
Agrawal Nipun, Kumar Priyanka*, Singh K Atul and S. B. Gupta \\ Department of Community Medicine, SRMS IMS, Bareilly (UP), India \\ *Corresponding author
}

\begin{abstract}
A B S T R A C T
The proportion of people aged over 60 years is growing faster than any other age group in almost every country. of the estimated 57 million global deaths in 2008, 36million (63\%) were due to non-communicable diseases(NCDs). Diabetes mellitus (DM) refers to a group of common metabolic disorders that share the phenotype of hyperglycaemia. Type $2 \mathrm{DM}$ is preceded by a period of impaired fasting glucose (IFG) or impaired glucose tolerance (IGT), and a number of lifestyle modifications and pharmacologic agents prevent or delay the onset of DM. Older people in developing countries have around three times the number of years lost to premature death from heart disease, stroke, and chronic lung disease. With this background current study was planned to find prevalence of diabetes in elderly rural population and also associated risk factors. This descriptive cross-sectional study was conducted over a period of one year among all the families registered in the field practice area of RHTC SRMS IMS at Bareilly, Uttar Pradesh including 263 persons aged 60 years or more. Rural areas were selected randomly and complete house to house survey and face-to-face interview were conducted. The prevalence of diabetes mellitus in rural was found to be $23.95 \%$. Diabetes was found to have positive association with increasing age, better education, being businessman, daily consumption of oil, better socio-economic status and sedentary occupational physical activity. The prevalence of diabetes mellitus in rural was found to be $23.95 \%$. Diabetes was found to have positive association with increasing age, better education, being businessman, daily consumption of oil, better socio-economic status and sedentary occupational physical activity.
\end{abstract}

\section{Introduction}

The proportion of people aged over 60 years is growing faster than any other age group in almost every country which can be attributed to longer life expectancy, declining birth rates, expansion of healthcare services in quality and quantity. Population ageing not only tells a success story of public health policies and of socioeconomic development, but also poses challenges on the society to adapt, in order to maximize the health and functional capacity of older people as well as their social participation and security. ${ }^{1}$

Of the estimated 57 million global deaths in 2008, 36million (63\%) were due to noncommunicable diseases (NCDs). Population growth and increased longevity are leading to a rapid increase in the total number of middle- 
aged and older adults, with a corresponding increase in the number of deaths caused by NCDs. The total number of annual NCD deaths is projected to reach 55 million by 2030 - whereas annual infectious disease deaths are projected to decline over the next 20 years.

In terms of attributable deaths, the leading behavioural and physiological risk factors globally are raised blood pressure (to which $13 \%$ of global deaths are attributed), followed by tobacco use (9\%), raised blood glucose $(6 \%)$, physical inactivity $(6 \%)$ and being overweight or obese $(5 \%){ }^{2}$

Diabetes mellitus (DM) refers to a group of common metabolic disorders that share the phenotype of hyperglycaemia. Type $2 \mathrm{DM}$ is preceded by a period of impaired fasting glucose (IFG) or impaired glucose tolerance (IGT), and a number of lifestyle modifications and pharmacologic agents prevent or delay the onset of DM. The Diabetes Prevention Program (DPP) demonstrated that intensive changes in lifestyle (diet and exercise for 30 $\mathrm{min} / \mathrm{d}$ five times/ week) in individuals with IGT prevented or delayed the development of type 2 DM by $58 \%$ compared to placebo. This effect was seen in individuals regardless of age, sex, or ethnic group. ${ }^{3}$

Older people in developing countries have around three times the number of years lost to premature death from heart disease, stroke, and chronic lung disease. They also have much higher rates of visual impairment and hearing loss. Many of these problems can be prevented easily and cost effectively by changing the lifestyle and adopting healthier habits. Good health is the key if older people are to remain independent and play an active part in family and community life. Health promotion and disease prevention activities for life can prevent or delay the onset of noncommunicable and chronic diseases, such as heart disease, stroke and cancer. ${ }^{4}$
With this background current study was planned to find prevalence of diabetes in elderly rural population and also associated risk factors.

\section{Materials and Methods}

This descriptive cross-sectional study was conducted over a period of one year among all the families registered in the field practice area of RHTC of Department of Community Medicine, Shri Ram Murti Smarak Institute of Medical Sciences (SRMS IMS) at Bareilly, Uttar Pradesh including all persons aged 60 years or more.

The prevalence of diabetes amongst elderly aged 60 years or more was found to be $18.8 \%$ in a study conducted by Singh, et al., ${ }^{5}$ Based on these figures, a sample size of 258 was calculated with an allowable error of $5 \%$ and applying the standard formula.

An instrument for the survey was developed after reviewing the available literature.

Rural areas were selected randomly from the areas served by Rural Health Training Centre under Department of Community Medicine, SRMS IMS using lottery method. Complete household-wise lists of inhabitants of the areas was generated and all the elderly aged 60 years and above meeting the inclusion criteria were surveyed till the desired sample size was achieved.

House to house visits were made and face-toface interview were conducted in the presence of one family member, preferably care-taker of the elderly or closely related. Presence of morbidity was elicited by self-reporting, supplemented by history, clinical examination and scrutiny of relevant medical records and documents.

Random blood sugar was done by glucometer on the spot and any person having random 
blood sugar level $\geq 200 \mathrm{gm} / \mathrm{dL}$ along with any of the symptoms of diabetes mellitus, including polyuria, polydipsia, polyphagia, extreme fatigue, blurry vision, cuts/bruises that are slow to heal and tingling/pain/ numbness in the hands/feet, was classified as diabetic. Already diagnosed cases, whether taking hypoglycaemic drugs or not, were also considered for the study. ${ }^{6}$

Data were entered using Microsoft Excel 2010 and statistical analysis was done using IBM SPSS v 20.0.0. Categorical variables were analysed using proportions and percentages. Association between categorical variables was established by Chi square and odds ratio (OR) with 95\% confidence intervals (CI) where applicable. Continuous variables were summarized by mean and standard deviation (SD), and association tested by parametric tests.

\section{Results and Discussion}

Table.1 shows the distribution of elderly according to the area surveyed

Table. 2 shows that majority $(86.7 \%)$ of the geriatric subjects are in the age group $60-70$ years followed by $71-80$ years $(10.33 \%)$.Proportion of elderly in higher age groups is significantly lower. The eldest geriatric subject is 96 years old female from Miyanpur village.

The mean age of elderly residing in the Rural areas are $66.21 \pm 5.97$

Table 3 shows socio-demographic characters of the study population. Proportion of subjects married and living with their spouse is $74.9 \%$. Proportion of those geriatric subjects who had lost their spouse is $22.8 \%$. The religion of approximately half of the study subjects was Hindu. Socio-economic status (SES) is assessed using Standard of Living Index
(SLI).The most of the elderly belonged to Medium SES (70.7\%).Maximum number of elderly had not received any formal schooling (32\%) and the proportion decreased as the educational level increased. Occupation of majority of subjects was housewives followed by landless agricultural labourers and other labourers.

In the logistic regression model, diabetes was found to have positive association with increasing age, better education, being businessman, daily consumption of oil, better socio-economic status and sedentary occupational physical activity while it had negative association with physically demanding occupations like labourer and five or more combined servings of fruits and vegetables. No association was seen between hypertension and gender, religion, marital status, educational status, daily salt consumption, Holmes and Rahe Stress Score, Independence in activities and instrumental activities of daily living, AUDIT Score, use of tobacco, support from family, how expenses are met and living arrangements.

Hosmer and Lemeshow Goodness-of-fit Test showed that the logistic regression model fit well in the situation and on the data. The Cox \& Snell R Square value of 0.565 also shows that the regression line fits well to the data.

In the present study, the total subjects surveyed are 263 from Rural and out of these $129(49.05 \%)$ were females and $134(50.95 \%)$ were males. It is in accordance with the WHO Multi-centric study done to establish epidemiological data on health problems in elderly ${ }^{13}$ in which rural area had females and males proportions of $55.6 \%$ and $44.4 \%$ respectively.

The mean age of rural population was $66.21 \pm 5.97$ years, and the oldest geriatric subject was 96 years old female from 
Miyanpur village. This too was similar to the WHO Multicentric study in elderly in which also mean age of males was found to be greater than mean age of females. ${ }^{13}$

Table.1 Distribution of study subjects according to place of living

\begin{tabular}{|l|c|c|c|c|}
\hline Name of village & Population & Elderly & $\begin{array}{c}\text { Families } \\
\text { visited }\end{array}$ & $\begin{array}{c}\text { Elderly } \\
\text { interviewed }\end{array}$ \\
\hline Miyanpur & 992 & 58 & 32 & 46 \\
\hline Ishapur & 2364 & 163 & 106 & 147 \\
\hline Parsunagla & 1226 & $\mathbf{8 0}$ & 49 & $\mathbf{7 0}$ \\
\hline Total & 4582 & 301 & 186 & 263 \\
\hline
\end{tabular}

Table.2 Distribution of study subjects according to age and gender

\begin{tabular}{|l|c|c|c|c|}
\hline \multicolumn{1}{|c|}{ Age } & Female & Male & Total & Percentage \\
\hline $\mathbf{6 0} \mathbf{- 7 0}$ & 112 & 116 & 228 & 86.7 \\
\hline $\mathbf{7 1} \mathbf{- ~ 8 0}$ & 11 & 16 & 27 & 10.3 \\
\hline $\mathbf{8 1 +}$ & 6 & 2 & 8 & 3.0 \\
\hline Total & 129 & 134 & 263 & 100.0 \\
\hline
\end{tabular}

Table.3 Distribution of study subjects according to socio-demographic characters

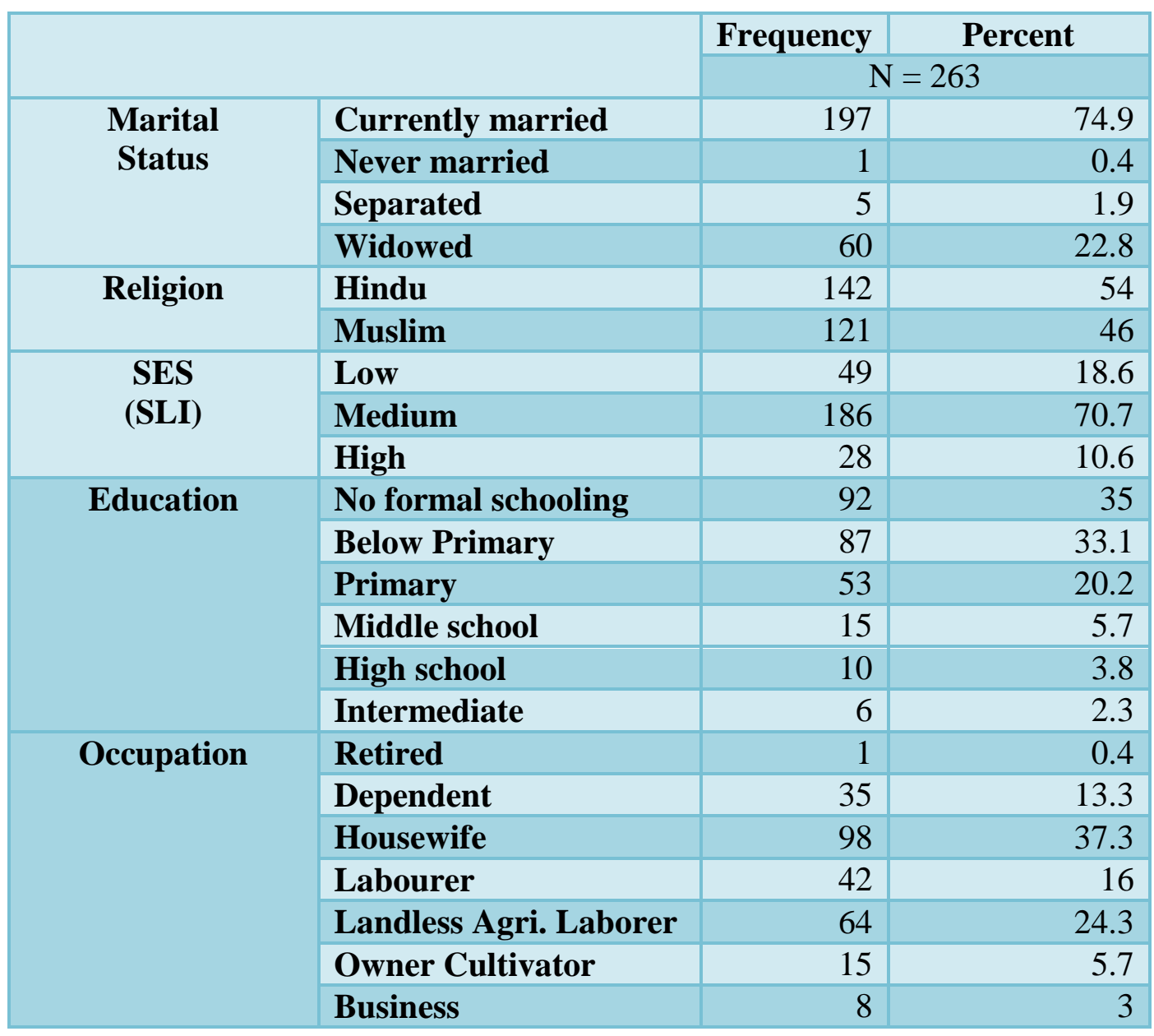


Table.4 Logistic Regression Analysis of 263Elderlies residing in Rural areas for Diabetes

\begin{tabular}{|c|c|c|c|c|c|}
\hline & & \multirow[t]{2}{*}{ B } & \multirow[t]{2}{*}{$\begin{array}{l}\text { ODD's } \\
\text { Ratio }\end{array}$} & \multicolumn{2}{|c|}{$\begin{array}{l}\text { 95\% C.I. for } \\
\text { ODD's Ratio }\end{array}$} \\
\hline & & & & Lower & Upper \\
\hline \multirow{3}{*}{ Age } & $60-70$ & & 1.00 & & \\
\hline & $71-80$ & 0.09 & 1.09 & 0.51 & 1.34 \\
\hline & $>80$ & 0.16 & 1.17 & 0.55 & 1.42 \\
\hline \multirow[t]{2}{*}{ Gender } & Female & & 1.00 & & \\
\hline & Male & -0.09 & 0.91 & 0.42 & 1.16 \\
\hline \multirow[t]{2}{*}{ Religion } & Hindu & & 1.00 & & \\
\hline & Muslim & -0.03 & 0.97 & 0.45 & 1.22 \\
\hline \multirow{4}{*}{ Marital status } & Currently married & & 1.00 & & \\
\hline & Widowed & -0.14 & 0.87 & 0.40 & 1.12 \\
\hline & Never Married & 0.04 & 1.04 & 0.48 & 1.29 \\
\hline & Seperated & -0.05 & 0.95 & 0.44 & 1.20 \\
\hline \multirow{6}{*}{ Educational status } & No formal education & & 1.00 & & \\
\hline & Below Primary & 0.03 & 1.03 & 0.48 & 1.28 \\
\hline & Primary & -0.06 & 0.94 & 0.43 & 1.19 \\
\hline & Middle School & 0.09 & 1.09 & 0.51 & 1.34 \\
\hline & High School & 0.15 & 1.16 & 0.54 & 1.41 \\
\hline & Intermediate & 0.21 & 1.23 & 0.58 & 1.48 \\
\hline \multirow[t]{6}{*}{ Occupation } & Dependent/Retired & & 1.00 & & \\
\hline & Housewife & 0.09 & 1.09 & 0.51 & 1.34 \\
\hline & Labourer & -0.16 & 0.85 & 0.39 & 1.10 \\
\hline & Business & 0.24 & 1.27 & 0.60 & 1.52 \\
\hline & Owner Cultivator & -0.05 & 0.95 & 0.44 & 1.20 \\
\hline & Landless Agri Laborer & -0.15 & 0.86 & 0.39 & 1.11 \\
\hline \multirow{5}{*}{$\begin{array}{l}\text { Daily Oil } \\
\text { Consumption (gms) }\end{array}$} & $\leq 10$ & & 1.00 & & \\
\hline & $10-20$ & -0.02 & 0.98 & 0.45 & 1.23 \\
\hline & $20-30$ & 0.10 & 1.11 & 0.52 & 1.36 \\
\hline & $30-40$ & 0.16 & 1.17 & 0.55 & 1.42 \\
\hline & $>40$ & 0.20 & 1.22 & 0.57 & 1.47 \\
\hline \multirow{5}{*}{$\begin{array}{l}\text { Daily Salt } \\
\text { Consumption (gms) }^{7}\end{array}$} & $\leq 5$ & & 1.00 & & \\
\hline & $5-7$ & 0.05 & 1.05 & 0.49 & 1.30 \\
\hline & $7-9$ & -0.04 & 0.96 & 0.44 & 1.21 \\
\hline & $9-11$ & 0.10 & 1.11 & 0.52 & 1.36 \\
\hline & $>11$ & -0.08 & 0.92 & 0.42 & 1.17 \\
\hline
\end{tabular}




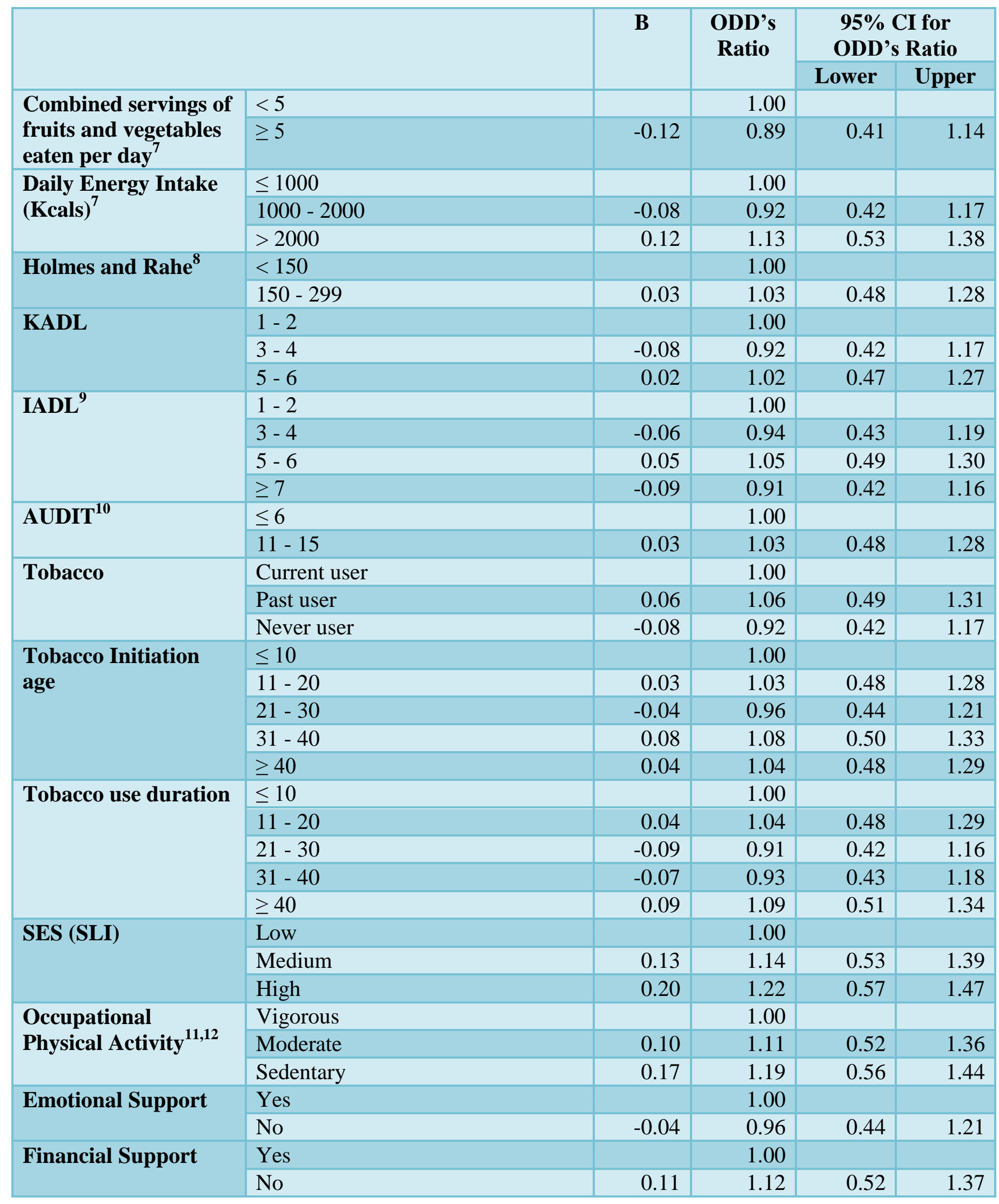




\begin{tabular}{|c|c|c|c|c|c|}
\hline & \multirow[t]{2}{*}{ B } & \multirow[t]{2}{*}{$\begin{array}{l}\text { ODD's } \\
\text { Ratio }\end{array}$} & \multicolumn{2}{|c|}{$\begin{array}{l}\text { 95\% CI for } \\
\text { Odd's Ratio }\end{array}$} \\
\hline & & & & Lower & Upper \\
\hline \multirow[t]{2}{*}{ Meet expenses } & Self earning & & 1.00 & & \\
\hline & Supported by family & 0.09 & 1.09 & 0.51 & 1.34 \\
\hline \multirow[t]{5}{*}{ Living arrangement } & Alone or with Children & & 1.00 & & \\
\hline & with Spouse & 0.04 & 1.04 & 0.48 & 1.29 \\
\hline & with Spouse and Children & -0.08 & 0.92 & 0.42 & 1.17 \\
\hline & with Children and Grand Children & 0.11 & 1.12 & 0.52 & 1.37 \\
\hline & $\begin{array}{l}\text { with Spouse, Children and Grand } \\
\text { Children }\end{array}$ & 0.08 & 1.08 & 0.50 & 1.33 \\
\hline
\end{tabular}

Table.5 Hosmer and Lemeshow Goodness-of-fit Test

\begin{tabular}{|l|l|l|l|}
\hline Step & Chi-square & df & Sig. \\
\hline $\mathbf{1}$ & 4.384 & 8 & .8209 \\
\hline \multicolumn{2}{|l}{ Cox \& Snell R Square } & 0.565 &
\end{tabular}

Majority (86.7\%) of the geriatric subjects are in the age group $60-70$ years followed by 71 - 80 years $(10.33 \%)$. The trend was similar to that found in the WHO Multicentric study in elderly and study by Khokhar, et $a l^{13,14}$

Marital status shows that the highest proportion of subjects (74.9\%) are married and living with their spouse followed by widowed subjects $(22.8 \%)$. There was one subject who was unmarried and few subjects $(1.9 \%)$ who were married but living separated from their spouse. It was contrary to the findings of WHO Multi-centric study in elderly in which percentage of those currently married was higher in urban areas (72.7\%) than in rural areas (68.2\%). It is also similar to findings of Lena A et al., (2009), Karnataka who reported $47.4 \%$ married and $43.7 \%$ widowed elderly subjects. ${ }^{13,15}$

Majority of elderly (54\%) belonged to the Hindu religion which is similar to study done by Barua A et al., (2007) who also reported maximum elderly subjects as Hindus $(80 \%){ }^{16}$

Most of the elderly had Medium SLI (70.7\%) followed by Low SLI (18.6\%) and High SLI (10.6\%) contradictory to the findings of Ajit NE et al., (2014), Bengaluru who reported highest proportion having High SLI followed by Medium and Low SLI. ${ }^{17}$

Occupational status of highest proportion of study subjects were housewives or homemakers (33.14\%) followed by labourers involved in work other than agriculture (25.33\%), followed by dependents $(18.48 \%)$, landless agricultural labourers (12.19\%), businessmen (6.67\%), owner cultivators $(2.86 \%)$ and retired people $(1.33 \%)$. This trend was similar to that reported by Ajit NE et $a l^{17}$.

The prevalence of diabetes mellitus in rural was found to be $23.95 \%$ slightly more than study of Singh AK et al (2012) Delhi, who had reported diabetes among elderly to be $18.8 \%$. In the logistic regression model, diabetes was found to have positive association with living in urban area, increasing age, better education, being businessman, daily consumption of oil, better socio-economic status and sedentary 
occupational physical activity while it had negative association with physically demanding occupations like labourer and five or more combined servings of fruits and vegetables. No association was seen between hypertension and gender, religion, marital status, educational status, daily salt consumption, Holmes and Rahe Stress Score, Independence in activities and instrumental activities of daily living, AUDIT Score, use of tobacco, support from family, how expenses are met and living arrangements. These observations were more or less similar to the observations of Islam R et al., (2012), Bangladesh. 5,18

In conclusion the prevalence of diabetes mellitus in rural was found to be $23.95 \%$. Diabetes was found to have positive association with increasing age, better education, being businessman, daily consumption of oil, better socio-economic status and sedentary occupational physical activity.

\section{References}

1. WHO, Health topics, Ageing.

2. World Health Statistics 2012. World Health Organization, Geneva, Switzerland. 2012. p. 34-35.

3. Powers AC. Harrison's Principles of Internal Medicine. $18^{\text {th }}$ ed. USA: The McGraw-Hill Companies, Inc.; 2012. p. 2975.

4. WHO, Question and answer archives, What are the public health implications of global ageing? [Online]. [cited 2013 Apr 12]; Available from: URL: http://www.who.int/features/qa/42/en/in dex.html

5. Singh AK, Mani K, Krishnan A, Aggarwal P. Prevalence, awareness, treatment and control of diabetes among elderly persons in an urban slum of Delhi. Indian Journal of Community
Medicine. 2012 Oct; 37(4): 236-9.

6. Diagnosing Diabetes and Learning About Prediabetes: American Diabetes Association [Internet]. 2014 [updated 2014 Mar 27; cited 2014 Jun 13]. Available from: http://www.diabetes.org/diabetesbasics/diagnosis/?loc $=$ db-slabnav

7. WHO STEPS Instrument (Core and expanded). The WHO STEPwise approach to chronic disease risk factor surveillance (STEPS). Geneva, Switzerland: World Health Organisation. 14 p.

8. Holmes TH, Rahe RH. The social readjustment rating scale. Journal of Psychosomatic Research. 1967; 11(2): 213-21.

9. Lawton MP, Brody EM. Assessment of older people: Self-maintaining and instrumental activities of daily living. The Gerontologist. 1969; 9(3): 179-186.

10. Babor TF, Higgins-Biddle JC, Saunders JB, Monteiro MG. The Alcohol Use Disorders Identification Test (AUDIT). Guidelines for Use in Primary Care. Geneva, Switzerland: Department of Mental Health and Substance Dependence, World Health Organization; 2001. Document no.: WHO/MSD/MSB/01.6a.

11. Moksha G. Classification on the basis of physical activity. [Online]. 2008 [cited 2013 Sept 26];[1]. Available from: URL:http://groundreport.com/classificat ion-on-the-baisis-of-physical-activity/

12. Guide to the Assessment of Rates of Veterans' Pensions (GARP). Canberra: Department of Veterans' Affairs; 2004. Chapter 16, Activities of Daily Living; p.219-23.

13. Multicentric study to establish epidemiological data on health problems in elderly.World Health Organization Collaborative Programme supported by the Government of 
India. [Online]. [cited 2013 May 30]; Available from: URL:http://www.whoindia.org/Li nkFiles/Health_Care_for_the_Elderly_ Multicentric_study_healthcareelderly.pd f.

14. Khokhar A, Mehra M. Life style and morbidity profile of geriatric population in an urbans community of Delhi. Indian J Med Sci. 2001 Nov;55(11):609-15

15. Lena A, Ashok K, Padma M, Kamath V, Kamath A. Health and social problems of the elderly: A crosssectional study in Udupi taluk, Karnataka. Indian Journal of Community Medicine. 2009 Apr; 34(2): p. 131-34.

16. Barua A, Mangesh R, Kumar $\mathrm{HNH}$,
Mathew S. A cross-sectional study on quality of life in geriatric population. Indian J Community Med 2007 Apr;32(2):146-147

17. Nisha Elizabeth Ajit, Nandish B, Roshan Joseph Fernandes, Gillian Roga, Arvind Kasthuri, Deepthi N Shanbhag et al., Prevalence of knee osteoarthritis in rural areas of Bangalore urban district. Internet Journal of Rheumatology and Clinical Immunology. 2014 Jan; 1(1).

18. Islam R, Rahman O. The risk factors of type 2 diabetic patients attending Rajshahi Diabetes Association, Rajshahi, Bangladesh and its primary prevention. Food and Public Health. 2012; 2(2): p. 5-11.

\section{How to cite this article:}

Agrawal Nipun, Kumar Priyanka, Singh K Atul and Gupta, SB. 2020. Prevalence of Diabetes and Associated Risk Factors in Elderly Rural Population. Int.J.Curr.Microbiol.App.Sci. 9(07): 1642-1650. doi: https://doi.org/10.20546/ijcmas.2020.907.189 